\title{
Research into the impact of biodiesel usage in transport on sustainable development
}

\author{
Z. Bazaras, A. Kersys, R. Kersys, N. Kersiene \& R. Raudys \\ Department of Transport Engineering, Kaunas University of Technology, \\ Lithuania
}

\begin{abstract}
Research into the use of alternative fuels such as rapeseed methyl ester (biodiesel) in the transport sector was performed on the basis of the estimated indicators for evaluating the impact and information of practical investigations. The main pollution sources were identified and it was determined that the priority pollutants were $\mathrm{CH}, \mathrm{CO}, \mathrm{CO}_{2}, \mathrm{NO}_{\mathrm{x}}$ and $\mathrm{SO}_{2}$. To calculate these pollutants' dispersion ISO 14001 is used to create an evaluation system and to select and pick up the appropriate data for the urban transport system CALPUFF model. Analysis of the impact of biodiesel usages in transport on sustainable development is presented in this paper.
\end{abstract}

Keywords: sustainable development, environment, biodiesel, air pollutants.

\section{Introduction}

Development of society to provide opportunities to satisfy the welfare of present and future generations by harmonizing environmental and economic issues, without exceeding allowable limits of environmental impact, are the main goals and tasks formulated in the Lithuanian National Sustainable Development Strategy.

The environmental challenges faced by Europe's urban areas are serious and have significant impacts on health and economic performance [1]. Current trends in some issues, such as air quality, are heading in the right direction although even here, nearly half of all EU citizens live in urban areas where existing air quality limits are breached with consequent impacts on human health.

The solution of ecological problems on the international level influences the development of new technologies, especially of a transport system. 
Processed from biomass, a renewable resource, biofuels are a direct substitute for fossil fuels in transport and can readily integrate into fuel supply systems [2-4]. Biodiesel can be used as an alternative fuel for transport.

\section{Environmental research of biodiesel usage in transport}

In the EU, transport is responsible for an estimated $21 \%$ of all air pollutants and greenhouse gases emissions that are contributing to global warming, and the percentage is rising. In order to meet sustainability goals, in particular the reduction of greenhouse gas emissions agreed under the Kyoto Protocol, it is essential to find ways of reducing energy consumption and emissions from transport. Nearly all the energy used in the EU transport sector comes from oil [5]. Oil reserves are limited - new reserves exists, but will mostly be more difficult to exploit. Further endeavors are needed to make reductions in the amount of energy used for transport. The evaluation of the role of biofuels in this context is the main goal of this research.

\subsection{Mathematical model of estimation of the air pollutants dispersion}

The negative influence of harmful substances to the environment is proportionate to their concentration in a layer of air above the ground. Concentration of the air pollutants is established in two ways: measuring experimentally, or calculating by using mathematical models. The first way is more reliable but does not establish the accurate concentration of pollutants over a wide area: measurements usually being taken from only a few points.

With the numerical modelling method more measuring points are made. By applying this method the analysis of a dispersion of the air pollutants can be made, not only of present conditions, but by a prognosis of the dispersion in the future.

Mathematical models can be made according to what form of measurement of air pollutants is intended - linear, dot, flat, or to what grade of a source - to industry, power or for transportation, and according to what level of calculation of concentrations are intended.

The system of the evaluation indicators was created considering various parameters of models - application, use, scale of application, use of the meteorological data, type of model, and period of modelling, by attributing some values.

- Applicability of model to a concrete source - grade and type of a source (geometrical form). Attributed values:

a) grade of a source: 1 - industry; 1 - power; 1 - transport;

b) type of a source: 1 - linear; 1 - dot; 1 - flat.

- Estimation of issues of the air pollutants - opportunities of the use of model. Values: 3 - for calculation of the major quantity of issues $\left(\mathrm{H}_{2} \mathrm{~S}, \mathrm{NH}_{3}, \mathrm{NO}_{\mathrm{x}}\right.$, $\mathrm{SO}_{2}$, organic connections); 2 - for calculation of the transports' emitted air pollutants; 1 - other (used for one air polluter). 
- Scale of application - estimation of three-dimensional scale of the model. Values: 4 - local; 3 - local-regional; 2 - regional-continental; 1 -global.

- Use of the meteorological data in the model. Values: 2 - it is estimated; 0 isn't estimated.

- Type of the model - the mathematical equation of model. Values: 3 - model of Gauss; 2 - model of Euler; 1 - model of Lagrange.

- Period of modelling - estimation of period of modelling. Values: 3 - year; 2 - day; 1 - hour; 0 - out.

The choice of mathematical models on system indicators has shown that models differ on applicability, scale of use, use of meteorological data, and the period of modelling. In transport systems the prime sources of pollution are locomotives, motor transport (concerned to linear sources of pollution), and ships. Ships are also linear sources while they are in the open sea. But having come into port and been moored to the quay, become a stationary, motionless source of pollution. At the quay in port, evaluating ships and the city's boilerhouses have been carried to dotted sources. Aspiring to estimate a dispersion of the unhealthy elements in port, it was obligatory that with the model it was possible to estimate pollution from linear and dotted sources of pollution.

The majority of the studied models estimate only one source of pollution (CAR-FMI, INPUFF), or some types of sources, but do not estimate linear and dotted simultaneously.

Table 1: Evaluation of the opportunities of the application and use of mathematical models.

\begin{tabular}{|c|c|c|c|c|c|c|c|}
\hline & \multicolumn{6}{|c|}{ Mathematical model } \\
\hline & & VARSA & CALPUFF & CONTLINK & ROADAIR & $\begin{array}{l}\text { CAR- } \\
\text { FMI }\end{array}$ & ISCST2 \\
\hline \multicolumn{2}{|l|}{ Use } & 3 & 2 & 2 & 2 & 2 & 3 \\
\hline \multirow{2}{*}{$\begin{array}{l}\text { Application for } \\
\text { concrete source }\end{array}$} & Grade & 2 & 3 & 1 & 1 & 1 & 2 \\
\hline & Type & 3 & 3 & 1 & 1 & 1 & 1 \\
\hline \multicolumn{2}{|c|}{ Scale of application } & 4 & 4 & 4 & 4 & 4 & 4 \\
\hline \multicolumn{2}{|c|}{ Meteorological data } & 2 & 2 & 2 & 2 & 2 & 2 \\
\hline \multicolumn{2}{|c|}{ Type of the model } & 3 & 3 & 3 & 3 & 3 & 3 \\
\hline \multicolumn{2}{|c|}{ Period of the modelling } & 0 & 3 & 3 & 1 & 1 & 3 \\
\hline \multicolumn{2}{|c|}{ Total } & 17 & 20 & 16 & 14 & 14 & 18 \\
\hline
\end{tabular}

The comparative analysis of the mathematical models shows (Table 1), that the most suitable for transport system in ports chooses model CALPUFF by which the dispersion of air pollutants from linear, dotted, volumetric and flat sources is estimated. 


\subsection{Impact of biodiesel usages in transport on sustainable development}

Research of the use of biodiesel (rapeseed methyl ester) in the transport sector was performed over a period of six month in 2006 . It was analyzed by ferry-boat transported cargo transport of a route of $8.75 \mathrm{~km}$ in length in the seaport transport system. Diesel engine work is evaluated using alternative fuels such as biodiesel.

Air pollutants dispersion in a seaport transport system is estimated by using the method of calculating the fuel consumption and emissions of the transport $[6,7]$.

General diesel consumption of cargo transport was calculated as

$$
B_{\text {Dcon }}=\sum_{i=1}^{n} n K_{\text {con, } i} S_{i}
$$

where $B_{D c o n} \quad$ - from age, design and engine of transport means dependent on general diesel consumption for traveled distance, $l$,
$n \quad$ - number of transport means,
$K_{c o n, i} \quad$ - from age and design of transport means dependent on diesel consumption for $1 \mathrm{~km}, \mathrm{l} / \mathrm{km}$.
$S_{i} \quad$ - traveled distance of the transport means, $\mathrm{km}$.

General biodiesel consumption of cargo transport calculated as

$$
B_{B D c o n}=\sum_{i=1}^{n} B_{D c o n} e
$$

where $B_{B D c o n} \quad$ - from age, design and engine of transport means dependent on general biodiesel consumption for traveled distance, $\mathrm{kg}$,

$e \quad-$ equivalence of biodiesel to diesel $(1 \mathrm{t}$ diesel $=1.11 \mathrm{RME})$ [3].

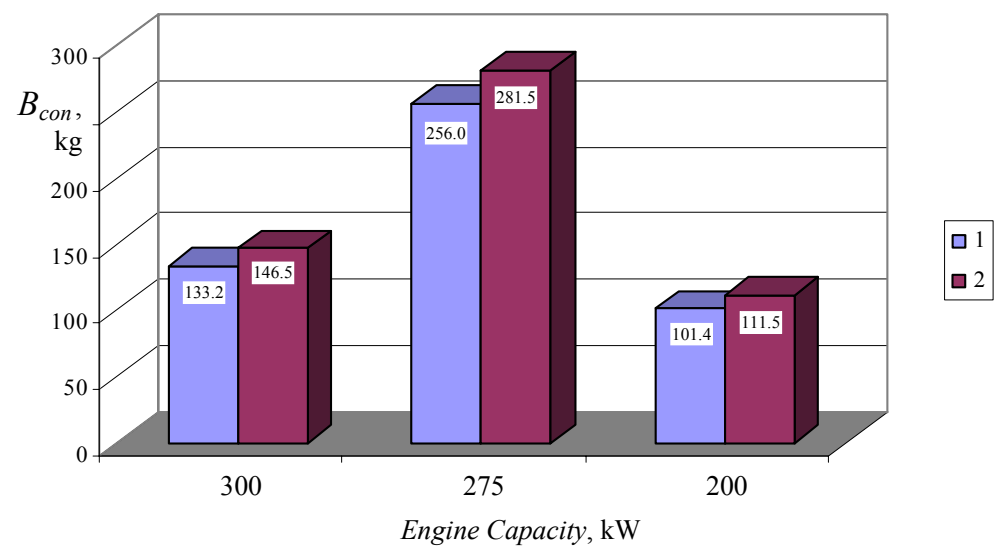

Figure 1: $\quad$ Fuel consumption by using diesel -1 in engines, and biodiesel -2 . 
General part of air pollutants, in the diesel engine using diesel for fuel, estimated from Eq. (3)

$$
B_{\text {Dpoll }}=\sum_{i=1}^{n} T_{D, i} B_{D c o n}
$$

where $T_{D, i} \quad$ - $\quad$ from engine of transport means dependent on part of air pollutants by burning of diesel in engine, $\mathrm{g} / \mathrm{kg}$.

General part of air pollutants, in the diesel engine using biodiesel as fuel, estimated from Eq. (4)

$$
B_{B D p o l l}=\sum_{i=1}^{n} T_{B D, i} B_{B D c o n}
$$

where $T_{B D, i} \quad$ - from engine of transport means dependent on part of air pollutants by burning of biodiesel in engine, $\mathrm{g} / \mathrm{kg}$.

The age of the first group of registered transport means is $2-5$ years (capacity of the engine $300 \mathrm{~kW})$, second - 6-10 years $(275 \mathrm{~kW})$ and third - over 10 years $(200 \mathrm{~kW})$. By analyzing the research results, it was estimated that the main air pollutants were $\mathrm{CH}, \mathrm{CO}, \mathrm{CO}_{2}, \mathrm{NO}_{x}$ and $\mathrm{SO}_{2}$.

Having calculated consumption of fuel, it was established that in the case of biodiesel used in the diesel engine, the consumption was $10 \%$ above that when using diesel.

Calculating of the air pollution showed that in the case of a biodiesel engine the quantity of $\mathrm{CH}$ decreased by $70 \%$, part of $\mathrm{CO}$ increased on average to $3.5 \%$, emission of $\mathrm{NO}_{\mathrm{x}}$ by $17.5 \%$ or more. Using $\mathrm{RME} \mathrm{CO}_{2}$ emission the number is the same as it is when absorbed from the atmosphere during rapeseed growing times.

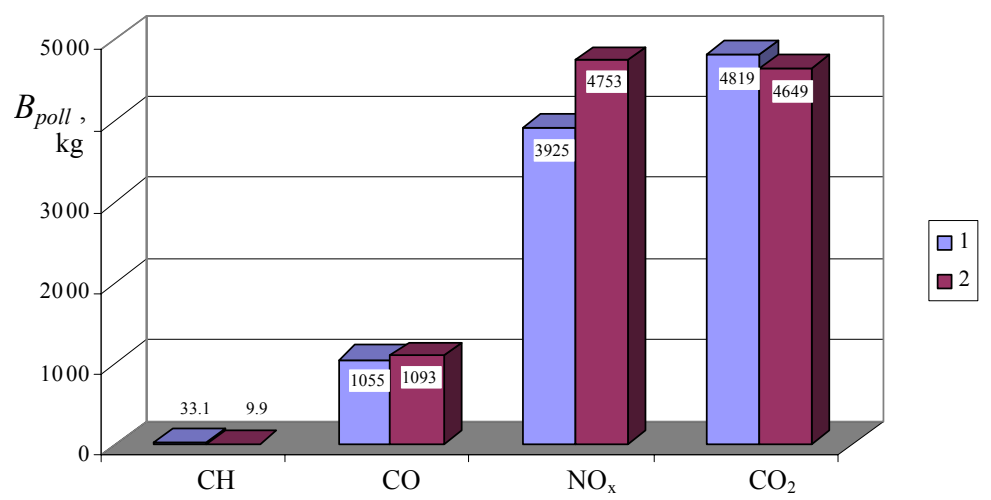

Figure 2: Air pollutants by using in diesel engines a diesel - 1, and biodiesel -2 . 
Biodiesel does not have any sulfur, whereas dieseline exhausts have $100 \%$ of it.

The use of biodiesel in a conventional diesel engine results in a substantial reduction of unburned hydrocarbons, carbon monoxide and particulate matter. The exhaust emissions of sulfur oxides and sulfates (major components of acid rain) from biodiesel are essentially smaller when compared to diesel. The disadvantages of using biodiesel in a diesel engine are a loss of power of between 2-3\%. The fuel consumption and emissions is given in Figures 1 and 2.

Modern diesel engine technology has advanced to the point where the advantages of biofuel usage are becoming much greater than the disadvantages. Modern diesel engines produce less noise, smoke or vibrations and they are more fuel-efficient than older model engines. Diesel engines have the added advantage of greater acceleration when compared to gasoline engines on the same model of vehicle. The use of biodiesel fuel may be the solution to the increasing transportation energy crisis, particularly in the farming and shipping transportation sectors.

Biodiesel fuel is a clean and affordable fuel for trucks, buses, farm equipment and other forms of heavy transportation. Biofuel refineries are much more simplistic and environmentally friendly in design than typical petrochemical refineries. With the continued rise of international fuel prices, biodiesel is set to become much more popular as a fuel option in the farming and transportation industries.

Results of experimental research have shown that the usage of biodiesel in the transport sector is a positive factor for sustainable development.

\section{Conclusions}

The main air pollutant sources of seaport transport systems were identified and it was determined that the dominant pollutants were $\mathrm{CH}, \mathrm{CO}, \mathrm{CO}_{2}, \mathrm{NO}_{\mathrm{x}}$ and $\mathrm{SO}_{2}$. To calculate these pollutants' distribution ISO 14001 was used to create the evaluation system and to select and pick up the appropriate data for the urban transport CALPUFF model.

Having used the irregular method for fuel consumption it was determined that the comparative fuel ratio of biodieseline was higher than for dieseline. Having calculated the pollution it was defined that using biodieseline the comparative $\mathrm{CH}$ quantity became less, but $\mathrm{CO}$ and $\mathrm{NO}_{\mathrm{x}}$ emission became higher than using dieseline. Using $\mathrm{RME} \mathrm{CO}_{2}$ emission number it is the same as is absorbed from the atmosphere during the growing of rapeseed. Biodieseline does not have any sulphur, whereas dieseline exhausts $100 \%$ of it.

Scientific research confirms, that biodiesel exhaust has a less harmful impact on human health than diesel fuel and is environmentally friendly. The use of biodiesel fuel may be the solution to the increasing transportation energy crisis and has a direct influence on sustainable development. 


\section{References}

[1] Quinet, E. Evaluation of environmental impacts. Handbook of transport and the environment. Elsevier, Amsterdam, Vol. 4, pp. 357-374, 2003.

[2] Bazaras, Z., Raudys, R., Aleksevicius, A. Modeling of spark ignition engines parameters using for fuel ethanol. Proc. of the $11^{\text {th }}$ Int. Conf. Mechanika, KTU Technologija: Kaunas, pp. 289-290, 2006.

[3] Kersys, A., Milius, Research of emissions by using in the diesel engine rapeseed methyl ester. Proc. of the $9^{\text {th }}$ Int. Conf. Transport means-2005, KTU Technologija: Kaunas, pp. 86-89, 2005.

[4] Gustavsson, L., Börjesson, P., Johansson, B., Svenningsson, P. Reducing $\mathrm{CO}_{2}$ emissions bz substituting biomass for fossil fuels. Energy International Journal, Vol. 20, pp. 1097-1113, 1995.

[5] http://www.europa.eu.int/comm/environment/urban/sustainable_urban_m anagement.htm.

[6] Delucchi, M.A. Emissions of criterium pollutants, toxic air pollutants, and greenhouse gases, from the use of alternative transportation modes and fuels. Davis: Institute of Transportation Studies, University of California.

[7] Sunder, L., Dhingra, K.V.K. Environmental impact assessment for sustainable transport. Handbook of transport and the environment. Elsevier, Amsterdam, Vol. 4, pp. 309-332, 2003. 